

Research Article

\title{
Flexural performance of wire mesh and geotextile-strengthened reinforced concrete beam
}

\author{
Ayesha Siddika ${ }^{1}$. Md. Hasibul Hasan Shojib ${ }^{1}$. Md. Mokbul Hossain ${ }^{1} \cdot$ Md. Israfil Hossain ${ }^{1}$. \\ Md. Abdullah Al Mamun ${ }^{2} \cdot$ Rayed Alyousef ${ }^{3}$ Y. H. Mugahed Amran ${ }^{3,4}$
}

(c) Springer Nature Switzerland AG 2019

\begin{abstract}
Strengthening of Reinforced Concrete Beam (RCB) for enhancing its flexural performance is a very popular technique to increase the structural life span. Optimization of the construction and strengthening cost without compromising the target strength and service life of a structure is now a matter of challenge for researchers. The wire mesh and geotextile materials possesses some good properties, such as cost-effectiveness, high strength-to-weight ratio, significant flexural performance, and compatibility with concrete, thus can be used as strengthening material. This experimental study aimed to investigate wire mesh and geotextile as strengthening materials for RCBs to enhance their flexural capacity. Three different types of strengthening configuration were used for each type of strengthening material. In order to examine the effectiveness of the wire mesh and geotextile as strengthening material, three point bending tests were done. This experimental results showed that the beams wrapped using wire mesh could enhance the flexural performance and reduce the deflection of RCBs without damage up to the reliable limit. Moreover, wire mesh layer in the tension face and U-wrapping system were proven as the effective configuration in the strengthening technique. The nonwoven geotextile strengthened-beams also had a moderate strength compared with wire mesh strengthened-beams. Nevertheless, the RCBs were found to be more flexible in nature, having a grip on concrete after failure occurred in concrete crushing when wrapped with geotextile layer. Therefore, RCB strengthening by incorporating wire mesh and geotextile materials is sustainable in terms of structural integrity and economic aspect.
\end{abstract}

Keywords Flexural strengthening · Reinforced concrete $\cdot$ Beam $\cdot$ Wire mesh $\cdot$ Nonwoven geotextile

\section{Introduction}

Reinforced concrete (RC) is the most used construction material. Improper design and critical loading and environmental conditions cause the lack of load carrying capacity of RC structures, which can be solved by strengthening techniques; to face the challenges from the occupant characteristics, degradation in materials; or needing additional safety precautions [1,2]. Most of the RC structural members undergo bending action in their service life due to different types of sustained load. Among them, beam elements may frequently fail due to their low flexural performance, which sometimes needs to be strengthened. To ensure the flexural failure of Reinforced Concrete Beam (RCB), generally it needed to design as a ductile member in order to resist bending under sustained loads. The ductile failure mode is more accepted than the brittle failure mode of RCBs; high reinforcement ratio in design may be favorable to enhance the flexural performance as well as ductility of RCBs [3].

$\triangle$ Ayesha Siddika, ayesha.ruet@yahoo.com; ayeshace@pust.ac.bd| ${ }^{1}$ Department of Civil Engineering, Faculty of Engineering and Technology, Pabna University of Science and Technology, Pabna 6600, Bangladesh. ${ }^{2}$ Department of Civil Engineering, Rajshahi University of Engineering and Technology, Rajshahi 6204, Bangladesh. ${ }^{3}$ Department of Civil Engineering, College of Engineering, Prince Sattam Bin Abdulaziz University, Alkharj 11942, Saudi Arabia. ${ }^{4}$ Department of Civil Engineering, Faculty of Engineering, Amran University, Quhal, Amran Province, Yemen. 
The flexural performance of RCBs can be enhanced by providing additional tensile strength along their tension face (generally soffit), which may enhance the ductile deformation under bending action. Jacketing is the most used strengthening technique applied to enhance flexural strength of the RCB [1]. Most of the metallic construction materials have high tensile strength. However, when selecting strengthening materials, the material must have bonding properties with the existing structure and sufficient sustainability should exist in terms of strength, durability, and cost. The currently available flexural strengthening materials are steel sheet/plate, ferrocement, fiber-reinforced polymer sheets/strips, epoxy polymers, and textile fabrics/fibers $[2,4-6]$. Most of them are high cost materials.

Nonwoven polypropylene geotextile fabric and woven wire mesh are selected for the present work. Generally, ferrocement have properties of high performance under load, cracking resistance, availability, high workability, and cost-effectiveness [3]. The performance of strengthened structures depends on the wire mesh used in ferrocement composite, which elaborately depends on the wire mesh orientation, wire direction, and thickness and layers of wire mesh used. Wire mesh is proven as a ductile material, which possesses full flexural strength when attached along the tension face of the beam with mortar with low tensile strength and sufficiently improves the ductile behavior of the beam [7]. Such strengthened beams are expected to have high flexural strength, high ductility ratio, enhanced energy absorption capacity, and reduced crack width with large deflection resistance up to failure [8]. Saadi et al. [2] found $18.3 \%$ increase in load carrying capacity of RCB when strengthened by attaching steel wire mesh using mortar along the soffit of the beam. Additionally, increasing the reinforcement ratio after using a steel wire mesh layer along tension face can improve the flexural performance and ductility of RCBs [9]. Xing et al. [5] tested RCBs strengthened in flexure by wire mesh of different areas and found that the flexural strength of strengthened beams increased with the number of wires. The authors observed 6-15\% increase in load carrying capacity and decrease in the strain, which could increase the serviceability of the strengthened beams up to $200 \%$. Failure of these specimens was generally controlled by the sudden debonding of wire mesh from the concrete, which should be controlled to obtain the full advantage of strengthening. Increasing the number of wire mesh not only improves the flexural strength but also the overall energy absorption capacity of the beam [7]. The improvement of flexural strength and moment carrying capacity considerably enhances in over-reinforced beams compared with beams with balanced reinforcement ratio and only slightly improves under-reinforced beams [8].
Therefore, selection of strengthening system should conforms all these criteria.

Meanwhile, textile-reinforced concrete layer is used in strengthening of existing load bearing structure because it efficiently increases the tensile strength and deformability of RC structures and reduces cracks width [10]. Geotextiles consist of synthetic fibers, such as polypropylene $(75 \%)$, polyester $(20 \%)$, polythene, or in other combination [11]. Nonwoven polypropylene fibers have high tensile strength, which can influence the flexural performance along with additional resistance to adverse environmental effect [12]. Because, nonwoven geotextile (polypropylene fabric)-reinforced concrete reduces water penetration into the RC structure when used as a protective layer [10]. Textiles are needed along the high bending moment zone in RCBs with additional anchorage length to be strengthened in flexure [13]. These materials are cost-effective and locally available in rural areas worldwide, thereby lowering the construction equipment cost and are thus genuinely sustainable. This system of additional protection layer can be used in retrofitting bridge pillars and in waterproof and outdoor structures [10]. The improvement of energy absorption capacity, toughness, and ductility are also observed after using a textile-reinforced layer in concrete structures [12]. Quality and orientation of fibers are the most important parameters that affect the overall performance of reinforcing layer. Most of the studies have used textile mesh with fibers arranged in two or more directions to compose textile mortar or concrete cover along the tension face of RCBs for flexural strengthening [13]. In the present work, nonwoven geotextile fabrics are selected for RCB strengthening, because this type of geotextiles have large fibers and strongly bond with concrete, given a sufficient flow capability [14]. This bond can be easily formed by curing freshly mixed concrete over a geotextile sheet. The pore size of nonwoven geotextiles is between $0.1 \mathrm{~mm}$ and $0.2 \mathrm{~mm}$ [15]. Thus, grain size below $0.1 \mathrm{~mm}$ is recommended for cementitious matrix for attaching the nonwoven geotextile to the concrete structure. According to Zak et al. [10], who found the maximum infiltration of cementitious matrix when its maximum grain size was limited to $0.25 \mathrm{~mm}$. If the mix is compacted through mechanical vibration, then further anchorage would be produced through the infiltration of the cementitious mix, with the fibers in geotextile and concrete, thereby producing an average of $20 \%$ improvement in bonding strength $[10,14]$. Given the low elastic modulus of polypropylene fiber, geotextile fabric reinforcing cannot improve the post cracking characteristics of brittle structures, which results in strain softening in cement composites [12]. This protective layer can control $25 \%$ of strain without collapsing and make the RC structure ductile in nature [10]. Meanwhile, low tensile strength of these nonwoven geotextile fabrics 
(approximately $50 \mathrm{kN} / \mathrm{m}$ ) can be enhanced by producing composites from woven and nonwoven geotextiles [15].

Though there is several investigations on wire mesh strengthened beam, but in case of geotextile strengthening, there is no significant researches observed. Therefore, this study attempts to investigate the flexural performance of RCBs strengthened using wire mesh and nonwoven geotextile strengthening layer. In order to investigate the appropriate wrapping system, three different configuration of strengthening system were applied for each material.

\section{Material selection for strengthening scheme}

Readily available materials are suitable for the strengthening and construction of structures because they speed up the system and are easy to work with. Therefore, locally available and easily manufactured wire mesh for strengthening purposes is advantageous in characteristics, which are mentioned in the literature $[2,9,16]$. Compatibility between steel wire mesh and concrete is perfectly coordinated under loadings. Strength-to-weight ratio is extremely high from steel plate-strengthened structures. The application of wire mesh in strengthening concrete structure found cost-effective; because it does not requires special experts. As well, it possesses high bending strength and in-plane shear resistance capacity. Wire mesh possesses ductile nature; hence, the ductility of RC structures may increase up to the benchmark. After covering of mortar, the wire mesh thickness may be $1.5-3 \mathrm{~cm}$ [9]. Wire mesh provides extremely low self-weight compared with other steel plate materials for strengthening and is thus considered cost-effective. Wire mesh with $0^{\circ}$ orientation with the longitudinal axis of the beam shows the highest strength-to-cost ratio, whereas the $45^{\circ}$ orientation possesses higher load carrying and energy absorption capacities while strengthening RCBs in flexure [8]. Textile-reinforced concrete or mortar can be used as a cover for RCB strengthening to improve the flexural strength, ductility, and durability of the beam $[12,13,17]$. Textile mesh is the most used material for textile-reinforced mortar or concrete composites, which consist of fibers in two or more directions [13]. In view of nonwoven polypropylene fabrics, textile mesh possesses high tensile strength because of internal polypropylene fibers, and these fabrics reduce the effect of high concentration of fibers after combining with the cementitious mix [12]. These nonwoven geotextiles may be of $0.25-9 \mathrm{~mm}$ thickness and $50-1700 \mathrm{~g} / \mathrm{m}^{2}$ mass per unit area with $0.075-0.85 \mathrm{~mm}$ apparent opening size [11]. Nonwoven geotextiles possess high bonding strength with fine cementitious mix through infiltration and anchorage with the concrete structure. These protective layers can reduce water penetration and enhance flexural properties [10]. Having a low weight per unit area is also an advantage of textile reinforcement layers. Because of the above mentioned reasons, in the present study, wire mesh and nonwoven geotextiles were used for RCB strengthening works.

\section{Materials and methods}

\subsection{Preparation of specimens}

Concrete mix was prepared by integrating stone chips as coarse aggregates with maximum grain size of $12.5 \mathrm{~mm}$. Local fine river sand was used as fine aggregates with fineness modulus of 2.36. The used cement fulfills the requirements as per IS: 1489-1991 [18]. The single mix proportion 1:2:4 and water-cement ratio 0.5 was used to prepare concrete mix (M20) for all specimens. Specimens for compressive strength test were molded using a cylindrical mold with $100 \mathrm{~mm}$ diameter and $200 \mathrm{~mm}$ height. Tests were performed according to IS: 516-1959 [19] after 28 of days curing.

RCB specimens with size of $100 \mathrm{~mm} \times 100 \mathrm{~mm} \times 750 \mathrm{~mm}$ were prepared for testing the flexural strength of RCBs. The beam details were chosen to construct beams with low shear capacity and low flexural strength. The beams were reinforced with four 8-mm-diameter mild steel deformed bars, two of which were placed along the soffit, and the other two were placed at the top. Moreover, 6-mm-diameter bars were used as stirrups at $140 \mathrm{~mm}$ spacing. The yield strength and ultimate strength of the $6 \mathrm{~mm}$ steel reinforcement was $411 \mathrm{MPa}$ and $596 \mathrm{MPa}$ respectively; which were $423 \mathrm{MPa}$ and $625 \mathrm{MPa}$ respectively for $8 \mathrm{~mm}$ diameter bar. A $25 \mathrm{~mm}$ clear cover was used for placing the main reinforcement in all the specimens. Specimens were allowed to harden for $24 \mathrm{~h}$, and after that 28 days continuous water curing was performed by fully ponding. Total 3 cylindrical specimens and $21 \mathrm{RCB}$ specimens were casted for testing.

\subsection{Strengthening technique}

Nonwoven polypropylene geotextile fabric with pressurized thickness of $1.55 \mathrm{~mm}$ was used for strengthening. These geotextiles have maximum 35\% elongation and $700 \mathrm{~N}$ grab tensile strength. Woven wire mesh was constructed using 1.5-mm-diameter galvanized iron wire with $3 \mathrm{~mm}$ square openings. Wire mesh and geotextiles are shown in Fig. $1 a, b$ respectively. $R C B$ strengthening was performed after 28 days of curing of the prepared specimen for flexural testing. Geotextile and wire mesh were applied in three different configurations. The first 
Fig. 1 Strengthening materials

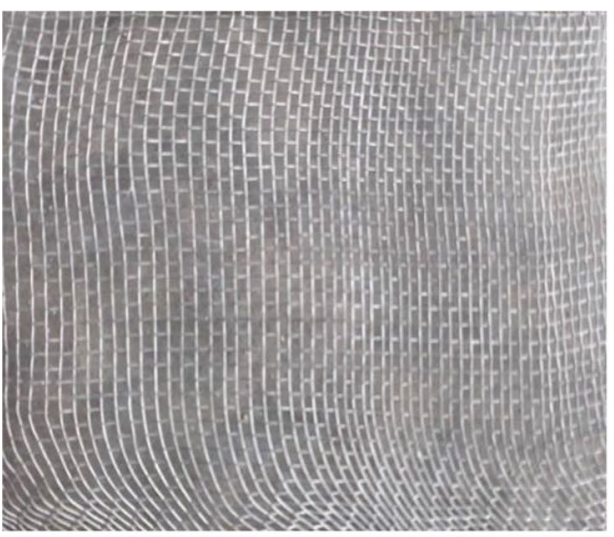

(a) Wire mesh

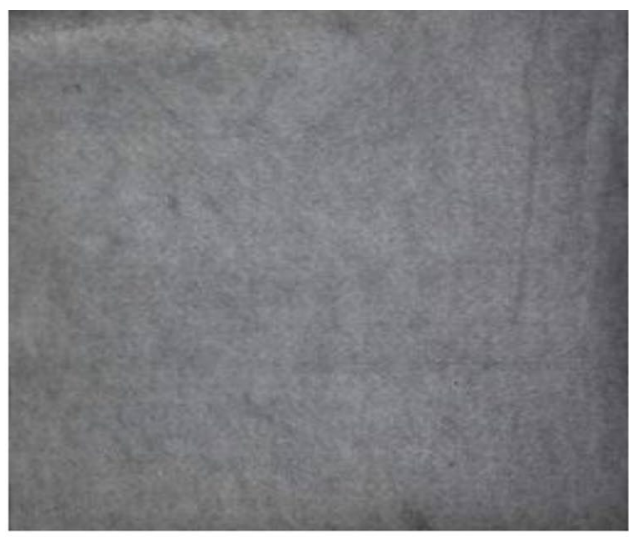

(b) Nonwoven geotextile strengthening was performed by applying geotextile or wire mesh along the tension face of the beams using a 10-mm-thick mortar. This mortar was prepared using Portland cement and very fine sand with proportion of $1: 2$. The second strengthening was performed in tension and compression faces, and the third strengthening was conducted by U-wrapping the beam by the strengthening material. Generally beams were failed due to the flexural and shear cracks under point loadings, where the flexural cracks seen within maximum moment region and propagates towards the upper fibers and the some of the shear cracks started form top of the beam and propagates towards bottom diagonally. For this reason these configurations were selected. Though the second strengthening scheme is not very practical, but in some cases during casting of new beams and the open compression face of beam can be strengthened by using this technique. Specifically, the second scheme was just used for comparison the effectiveness. All the strengthening configurations are shown in Fig. 2.

All the faces of the beams were prepared for strengthening via mechanical abrasion to increase the roughness and bonding with the additional strengthening layer. All the wire meshes were placed along $0^{\circ}$ orientation with the beam axis. Strengthening were applied for full length of each beam. After attaching the layers of geotextile fabric and wire mesh, all the beams were subjected to curing for 14 days and then tested for flexural strength.

\subsection{Flexural test on beams}

All the beams were tested for determining the load carrying capacity, flexural strength, deflection and cracking and failure patterns. Three point bending test were performed following the standards of ASTM C78 [20] for a clear span of $600 \mathrm{~mm}$.

\section{Results and discussions}

The average compressive strength of concrete cylinder after 28 days of curing for this experiment was $22.44 \mathrm{MPa}$. Table 1 lists the experimental results of the three specimens.

\subsection{Behavior of RCB under bending action}

RCB showed ductile behavior under bending action up to a certain limit of deflection. When steel started to yield, cracks started to become visible from the bottom of the beam under one point bending load. Tensile flexural cracks in concrete widen with the increase of load, and the beam could be deflected up to failure in concrete. All the RCBs failed in concrete crushing with steel yield. The cracking patterns and failure of RCB are shown in Figs. 3 and 4. These beams' failure mode can be defined as the flexural failure and showed a good shear resistance. Therefore, flexural strength should be improved to increase the ultimate load capacity under bending action. The flexural strength of the conventional RCB before strengthening was $20.565 \mathrm{MPa}$ (Table 2). The deflection of the beam under point load was 4-5 mm under ultimate loading condition. Wide distribution cracks were found in the load-deflection curve, as shown in Fig. 5. The load-deflection curve clearly showed that the beams underwent wide deflection after concrete crushing because the steel yielded rapidly after ultimate load without load increment. The confinement of concrete with ductile material may enhance the flexural performance of these beams.

\subsection{Performance of wire mesh-strengthened RCBs}

Table 3 lists the results of different strengthening systems. Wire mesh strengthening in tension face of the beam and U-wrapping performed better under bending 

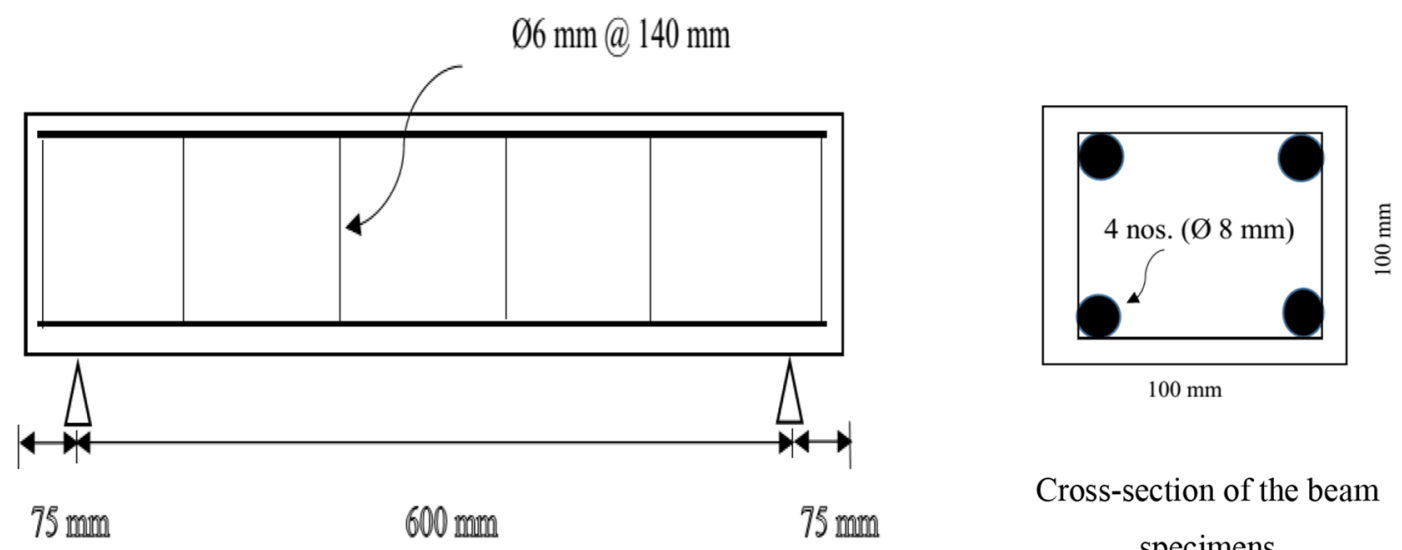

Cross-section of the beam specimens

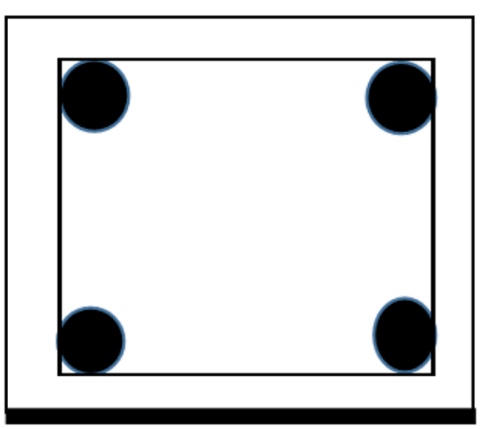

Strengthening configuration -1

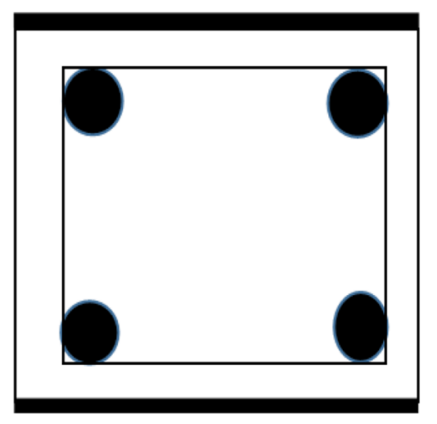

Strengthening configuration -2

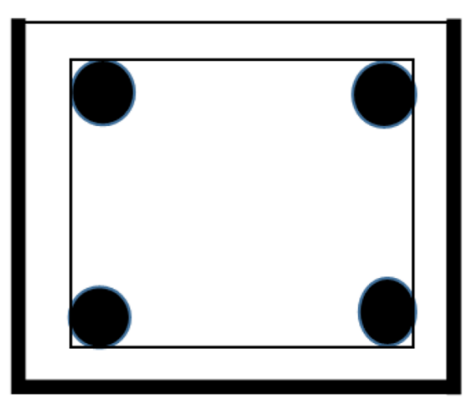

Strengthening configuration -3

Fig. 2 Strengthening configuration of RCBs

Table 1 Compressive strength of concrete cylinder

\begin{tabular}{llll}
\hline Mix proportion & $\begin{array}{l}\text { Speci- } \\
\text { men } \\
\text { no. }\end{array}$ & $\begin{array}{l}\text { Compressive } \\
\text { strength of con- } \\
\text { crete cylinder (MPa) }\end{array}$ & $\begin{array}{l}\text { Average com- } \\
\text { pressive strength } \\
\text { of concrete } \\
\text { cylinder (MPa) }\end{array}$ \\
\hline $1: 2: 4$ & 1 & 22.43 & 22.44 \\
& 2 & 21.80 & \\
3 & 23.10 & \\
\hline
\end{tabular}

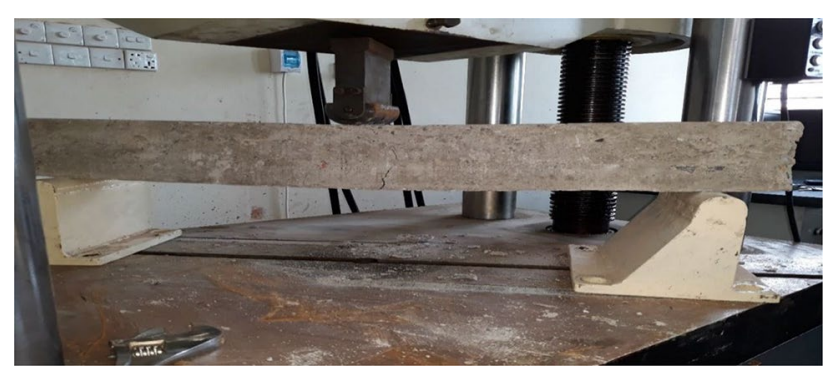

Fig. 3 Visible flexural cracks under point loading in RCBs

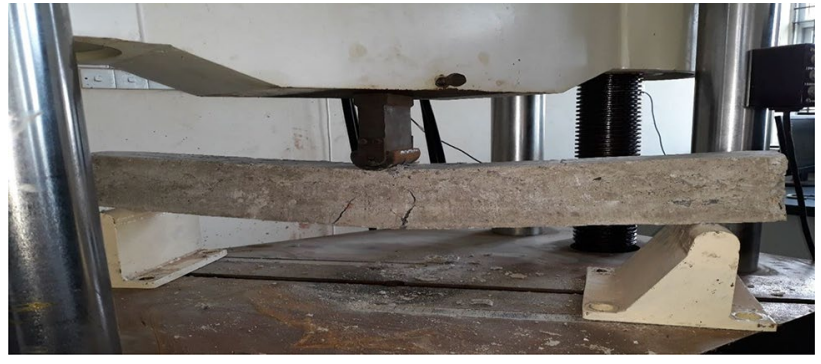

Fig. 4 Increased and widened flexural cracks with load in RCBs

action compared with the two side bonding techniques. Comparison of the control RCBs shows that the wire mesh in the tension face of the beam could resist nearly $80 \%$ more load at same deflection level at the beam midpoint. Meanwhile, U-wrapping strengthening could enhance the flexural strength two times more than the control beams. Initially, W1-type beams could resist more vertical deflection than the control beams but failure mode observed as the control beams. As shown in Fig. 6, W1-type beams started to deflect after the load reached at $20 \mathrm{kN}$; 
Table 2 Flexural strength of controlled RCBs

\begin{tabular}{llllll}
\hline Beam type & Specimen ID & $\begin{array}{l}\text { Ultimate load } \\
(\mathrm{kN})\end{array}$ & $\begin{array}{l}\text { Ultimate deflection at } \\
\text { mid span }(\mathrm{mm})\end{array}$ & $\begin{array}{l}\text { Flexural strength } \\
(\mathrm{MPa})\end{array}$ & \begin{tabular}{l} 
Average flexural strength (MPa) \\
\hline Control beam
\end{tabular} \\
& $\mathrm{C} 1$ & 24.6 & 4.3 & 22.14 & 20.565 \\
& $\mathrm{C} 2$ & 21.48 & 5.32 & 19.332 & \\
& $\mathrm{C} 3$ & 22.47 & 4.2 & 20.223 & \\
\hline
\end{tabular}


Fig. 5 Load-deflection curve of control RCBs

Table 3 Average flexural strength of wire mesh-strengthened beam

\begin{tabular}{|c|c|c|c|c|c|}
\hline Beam type & Wrapping System & Specimen ID & $\begin{array}{l}\text { Ultimate load } \\
(\mathrm{kN})\end{array}$ & $\begin{array}{l}\text { Ultimate deflection at } \\
\text { midspan }(\mathrm{mm})\end{array}$ & $\begin{array}{l}\text { Flexural } \\
\text { strength } \\
(\mathrm{MPa})\end{array}$ \\
\hline \multirow[t]{3}{*}{ Wire mesh-strengthened beam } & Tension face only & W1 & 44.09 & 5.16 & 39.681 \\
\hline & $\begin{array}{l}\text { Tension and compres- } \\
\text { sion faces }\end{array}$ & W2 & 46.37 & 2.5 & 41.733 \\
\hline & U-wrapping & W3 & 49.86 & 4.56 & 44.874 \\
\hline
\end{tabular}

subsequently, minimum deflection was found at peak load also. Failure mode in W1-type and W3-type beam is shown in Fig. 7 and Fig. 8 respectively, in which the post-cracking behavior of the control and the W1-type beams are comparable. Having an extremely thin layer of wire mesh and mortar resulted in failure before concrete cracking reach the ultimate limit and widening of the cracks after fracture in wire mesh occurred. Moreover, yielding of main steel rapidly progressed toward concrete failure. The ductility and ultimate strength of these beams increased with the wire diameter and mortar thickness. However, this result may sometimes cause a negative influence in strengthening performance because premature debonding may arise from excessive mortar thickness and improper curing [9]. High-strength mortar can reduce the concrete crack width and limit the deflection and strength capacity, thereby requiring further investigation. In W2-type specimen, force directly applied to the wire mesh layer along the top of beam, which creates a compression in the layer and caused debonding in the compression face. The failure of W2-type specimens in debonding is shown in Fig. 9. When the wire mesh layer started to debond from the compression face of the beam, diagonal cracks sometimes initiated and reached toward the bottom of the beam. This phenomenon may be caused by the porous concrete structure, which may lower the concrete strength; consequently 




Fig. 6 Load-deflection curve of W1-type beam

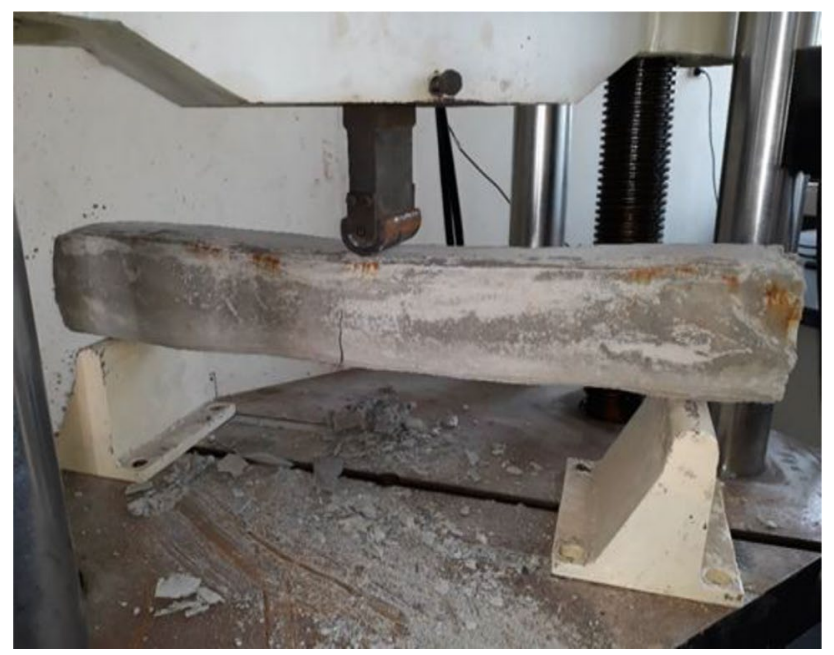

Fig. 7 Failure mode of W1-type beam

a low bonding with reinforcing steel and strengthening layer. However, most of the beams failed in debonding before flexural cracks widened. Nevertheless, these beams could carry slightly better load than the control specimen before failure in debonding occurred. For example, one of the W2-type specimen failed at $24.37 \mathrm{kN}$ load at a deflection of $10 \mathrm{~mm}$ before debonding occurred.

Meanwhile, in terms of the performance of $\mathrm{U}$-wrapped beams, it was showed a complicated failure mode. Initial flexural cracks were developed at early-stage load, and rapid widening of cracks was evident with the increase of beam deflection. Near-failure debonding started from the top compression face and propagated toward the support. However, one part of the compression face still had a grip in bonding, and no cracks or

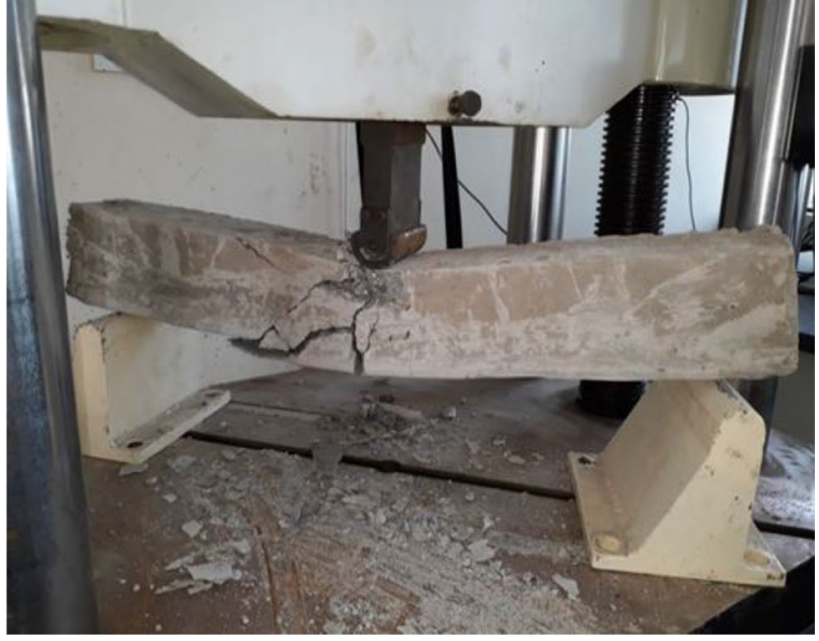

Fig. 8 Crack pattern in W3-type beam

signs of debonding were evident up to failure, as shown in Figs. 8 and 10. Therefore, debonding is less dependent on loading condition but highly dependent in bond strength with concrete. Debonding could have started from the weak point and propagated toward the high adverse stressed zone. All the flexural cracks widened immediately after fracture occurred in the wire mesh. Fracture of the wire mesh is comparable to brittle failure in this experiment because of the low thickness of the composite layer. Post-failure deflection of the control and W3-type beams were comparable, and both beams were deflected rapidly with the same load after failure due to steel yielding, as shown in Fig. 11. Therefore, the experimental results confirmed that RCB strengthening using wire mesh is advantageous. 


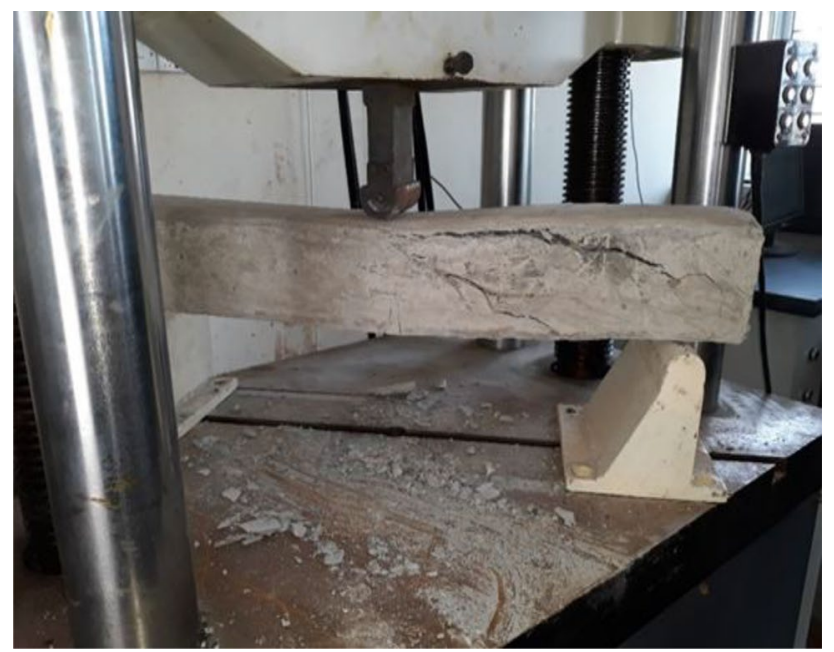

Fig. 9 Debonding failure in W2-type beam

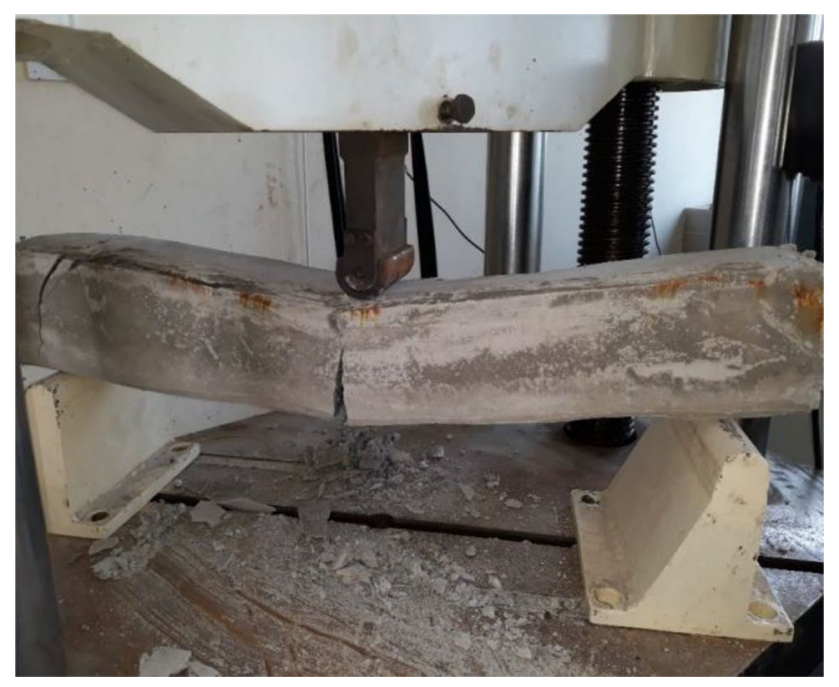

Fig. 10 Debonding and concrete crushing failure in W3-type beam

\subsubsection{Performance of geotextile-strengthened RCB}

Nonwoven geotextile-reinforced beams are highly ductile in nature. Geotextile bonding with concrete can sufficiently resist debonding up to concrete crushing. Geotextile strengthened-beam could resist extensive vertical deflection without fracture. High deformability of polypropylene fibers may enhance this behavior. The deformability of this fabric is higher than 30\% [21]. A 0-91\% increase in ultimate load carrying capacity was found in the experiment, which depended on the arrangement of strengthened layers (Table 4). A slight increase in strength was found in G1-type beam compared with the control beams. However, high deflection in the beam was found for this load. In Fig. 12, after cracks in concrete widened and reached failure, geotextile fabric had still not torn. Therefore, this ductile nature of geotextile could provide grip on concrete even after crushing occurs under loads. Similar results were found after testing G2-type beams. Failure of G2-type beams occurred at an average of 43.71 $\mathrm{kN}$ load when deflection of the beam was $12 \mathrm{~mm}$; nevertheless, geotextile did not crack or fracture. This advantageous nature of nonwoven geotextile can decrease the scattering of concrete when crushed under service load.

Meanwhile, G2-type beams were found as most effective in terms of strength gaining properties. However, the analysis of the failure mode of $\mathrm{G} 2$-type beams showed that geotextile fabric under load was delaminated from concrete due to slippage (Fig. 13). This result may be caused by the absence of compression capacity of geotextile. The disappointing matter resulted from G3-type beams. These beams failed at a lower load in comparison with G2-type beams but had higher capacity than control beams. The average flexural strength of G3-type strengthened beams was $33.498 \mathrm{MPa}$. One of the G3-type beams failed in concrete crushing and showed tearing of the geotextile

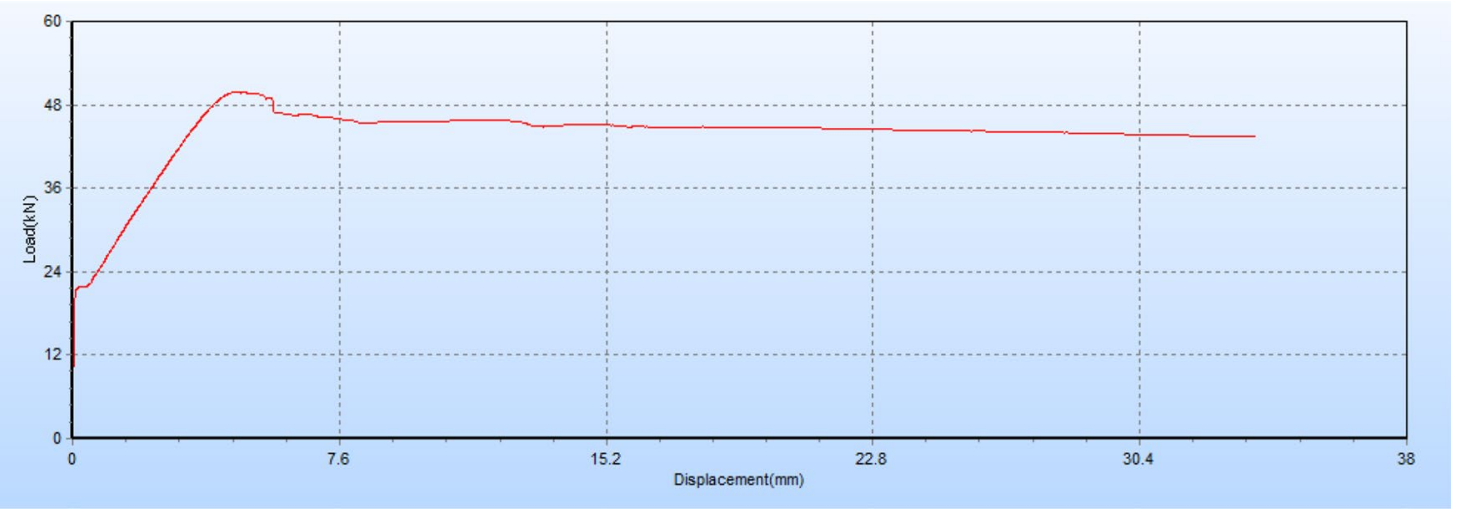

Fig. 11 Load-deflection curve of W3-type beam 
Table 4 Average flexural strength of geotextile strengthened-beam

\begin{tabular}{|c|c|c|c|c|c|}
\hline Beam type & Wrapping system & Specimen ID & $\begin{array}{l}\text { Ultimate load } \\
(\mathrm{kN})\end{array}$ & $\begin{array}{l}\text { Ultimate deflection at } \\
\text { midspan }(\mathrm{mm})\end{array}$ & $\begin{array}{l}\text { Flexural } \\
\text { strength } \\
(\mathrm{MPa})\end{array}$ \\
\hline \multirow[t]{3}{*}{ Geotextile strengthened-beam } & Tension face only & $\mathrm{G} 1$ & 24.73 & 19.8 & 22.257 \\
\hline & $\begin{array}{l}\text { Tension and compres- } \\
\text { sion faces }\end{array}$ & G2 & 43.71 & 12 & 39.339 \\
\hline & U-wrapping & G3 & 37.22 & 15.68 & 33.498 \\
\hline
\end{tabular}

Fig. 12 Failure pattern of G1 type beam

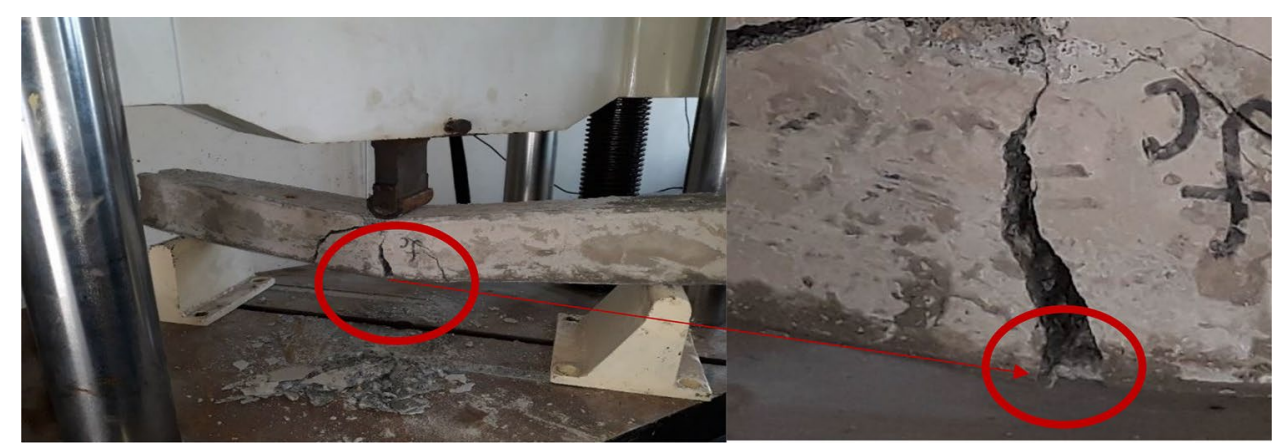

Fig. 13 Failure pattern of $\mathrm{G} 2$ type beam
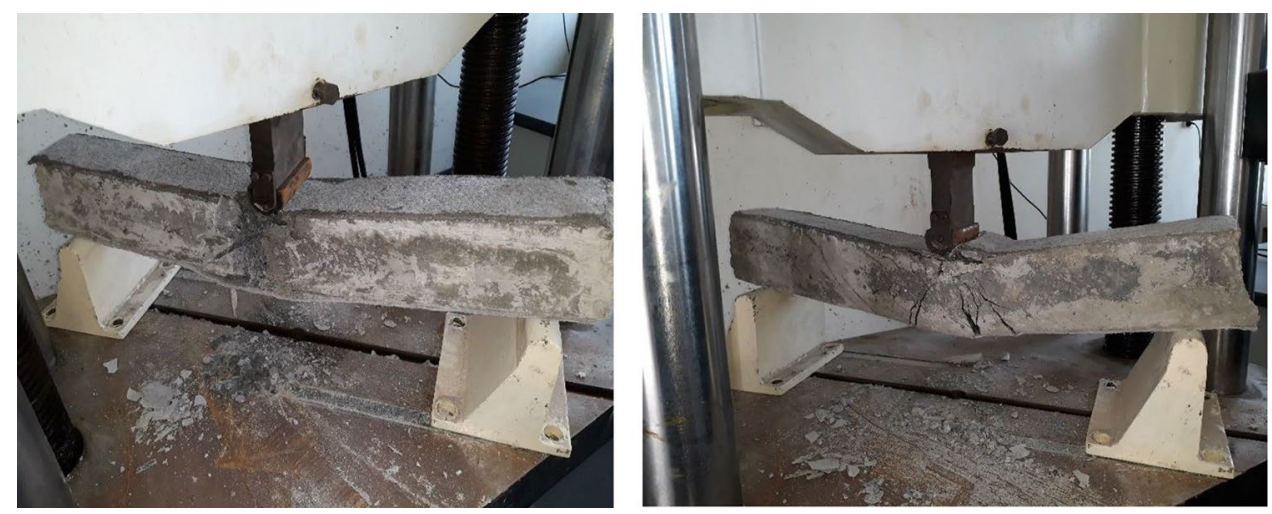

Fig. 14 Deflection pattern of G3 type beam
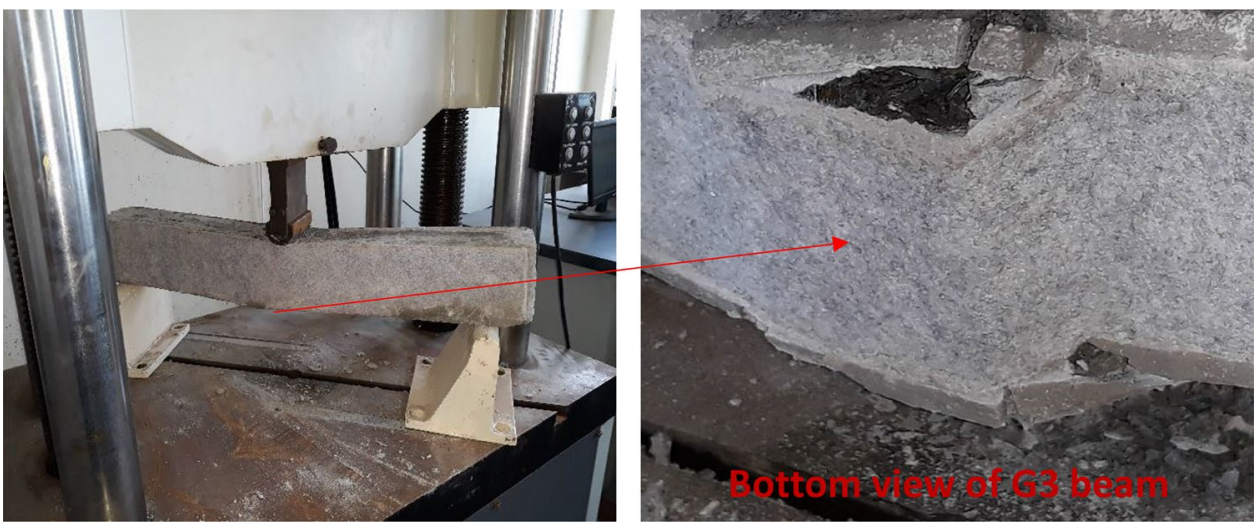

fabric along the bottom edges of the beam below the load point. The bonding between concrete and geotextile was assumed to be sufficient in this case. When cracks in concrete widened with load, geotextile extended up to its limit and tore along the most deflected section (Fig. 14). This occurrence was due to low fabric strength along the 
tear line. Nevertheless, the geotextile along the soffit of the beam did not crack even when the beam failed.

\section{Comparative performance}

\subsection{Load-deflection behavior}

When analyzing the load-deflection behavior of strengthened and non-strengthened beams, strengthening using wire mesh and geotextile undoubtedly increases the load and deflection carrying capacity. Wire mesh-strengthened beams were stiffer than those strengthened by geotextile in this experiment. Geotextile-strengthened beam could deflect more than 3-4 times from wire mesh strengthened beam before failure, as shown in Figs. 15, 16 and 17. Therefore, the failure mode of geotextile-strengthened beams could be considered ductile flexural failure, whereas control and wire mesh-strengthened beams' failure was found stiffer and less ductile. Among all the beams, a similarity was observed as their concrete crushed with steel yielding mode. Strength gain was considerably higher in wire



Fig. 15 Load-deflection curve of G1-type beam

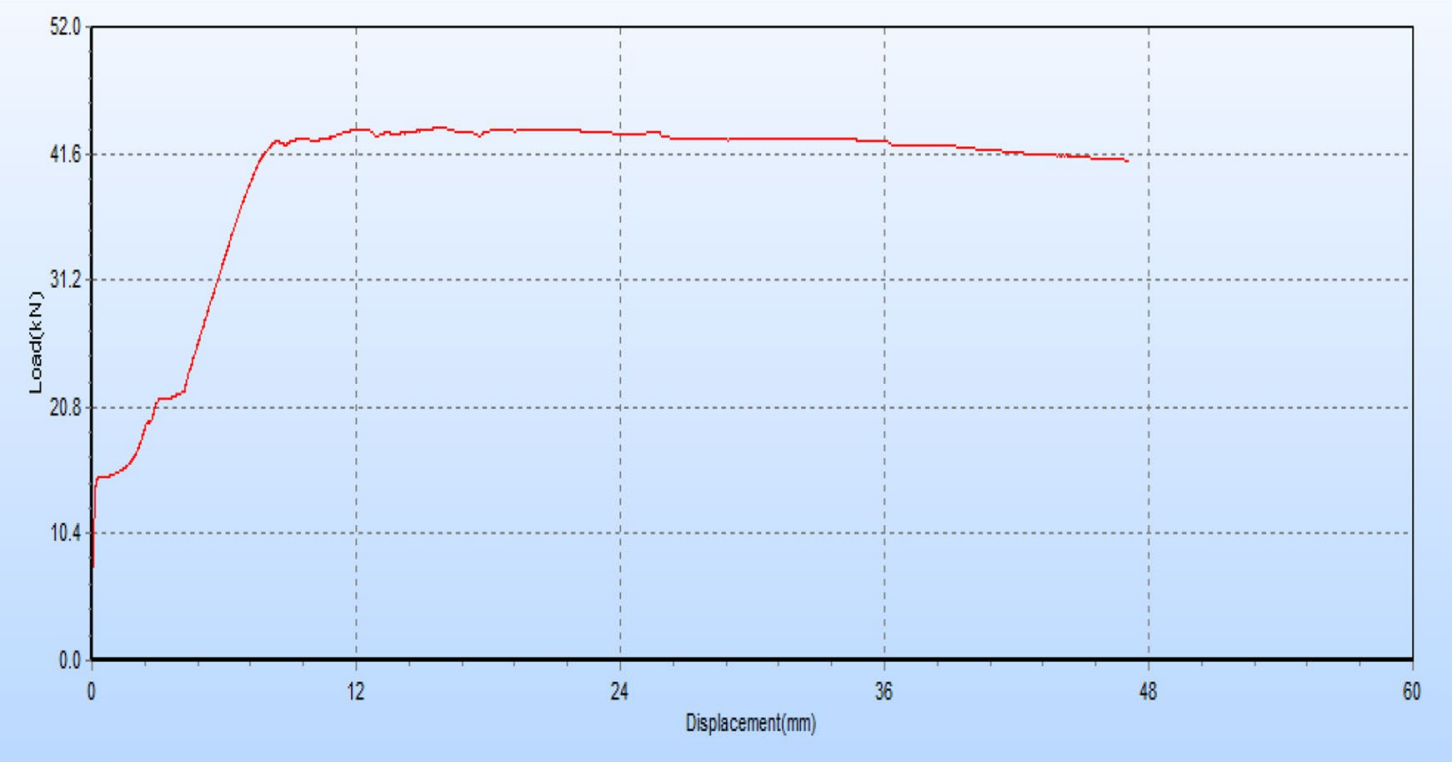

Fig. 16 Load-deflection curve of G2-type beam 


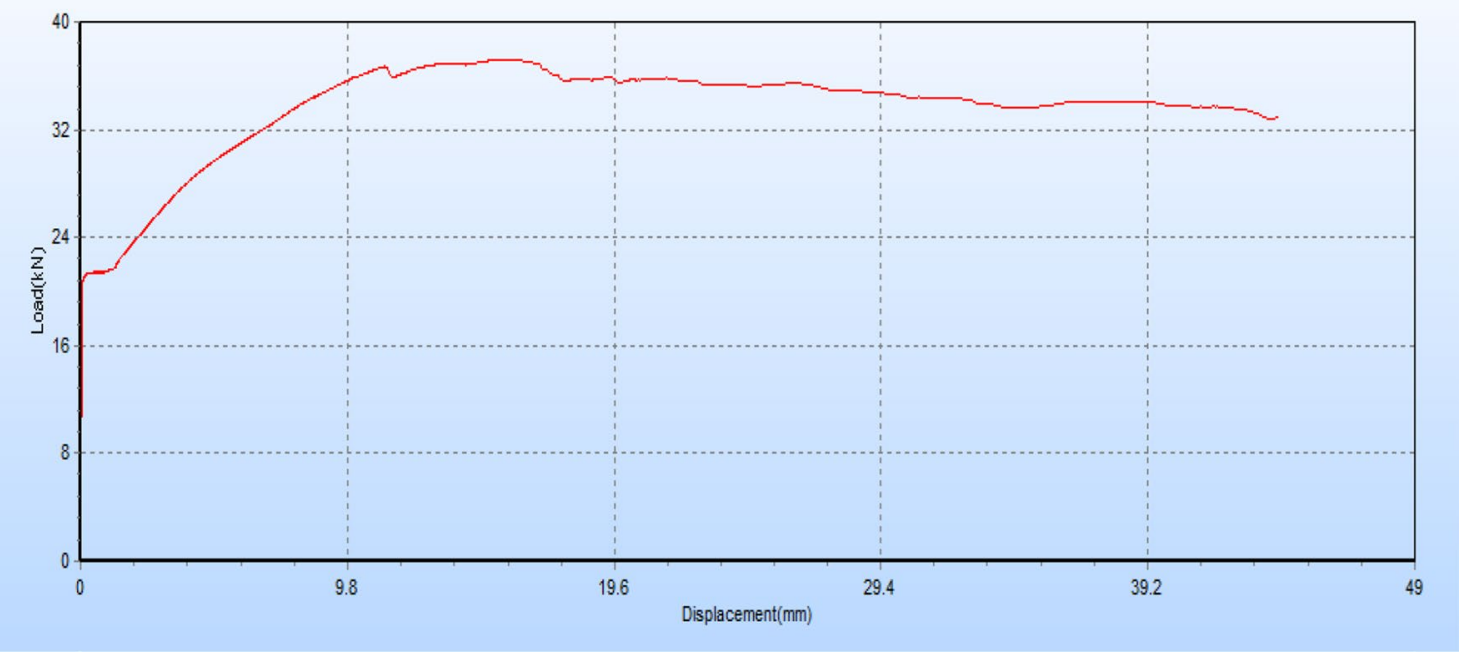

Fig. 17 Load-deflection curve of G3-type beam

mesh-strengthened beams than in geotextile-strengthened beams. However, the crack width at failure load was considerably lower for geotextile-strengthened beam than wire mesh-strengthened beams. This result was based on the typical set of experiment. Therefore, properties of wire mesh and geotextile were different and could change the performance of strengthened beam undoubtedly; hence, a direct comparison was invalid. Table 5 lists the comparative strength gain obtained from the average strength in the experiment.

\subsection{Efficiency of strengthening technique}

In this experiment, only cured specimens were strengthened using wire mesh wrapping by mortar. Therefore, wire mesh wrapping by mortar could be more effective than the proposed technique if the strengthened layer was applied during casting, as recommended by Khan et al. [3], who indicated that in situ strengthening technique is the most effective RCB strengthening using wire mesh wrapping. The problem associated with wire mesh and geotextile fabric strengthening techniques is that debonding may occur from concrete before reaching the ultimate strength of the beam. This phenomenon occurred in the experiment, thereby lowering the performance of the beam, especially wire mesh-wrapped beams. One layer of wire mesh could enhance the flexural performance for more than 40\%; however, premature debonding could destroy the overall strengthening system [9]. The use of adhesives resins or anchorage system may be a precaution. Particularly, the use of epoxy resin and shear connector may increase the composite action of RC members and wire mesh [7], thereby enhancing the overall flexural strength up to $123 \%$. Surface preparation considerably influences the overall debonding failure and thus requires further investigation. Nevertheless, wrapping material and beam need to act monolithically under an applied load to ensure the highest performance [1]. If the concrete is casted only on a geotextile sheet even without any treatment, then applying axial tensile load along the bond of concrete and nonwoven geotextile results in frequent tensile strength failure due to having bond strength more than tensile strength of the geotextile sheet [14]. This phenomenon may be comparable with the failure mode of G3-type beam. The experimental results show that the concrete with nonwoven geotextile fabric was highly ductile in nature, as supported by the study of Claramunt et al. [21]. This concrete's flexural strength and toughness could be more enhanced if an additional layer of nonwoven geotextile was used. Without any further investigation, direct comparisons of geotextile and wire mesh strengthened beams would be difficult. Nevertheless, on the basis of this study, wire mesh U-wrapped beams had the highest performance under bending action. The present study was standing for application one layer of wire mesh with mortar; but only one layer of wire mesh was found less
Table 5 Comparison in flexural strength of beams after strengthening

\begin{tabular}{llllllll}
\hline Parameter & \multicolumn{3}{l}{ Beam type } \\
\cline { 2 - 7 } & W1 & W2 & W3 & G1 & G2 & G3 \\
\hline \% Increment of flexural strength from control beam & 93 & 103 & 118 & 8 & 91 & 63 \\
\hline
\end{tabular}


effective in resisting concrete cracks under loads; therefore the thickness of wire mesh layer and diameter of wire should be well compatible with the objective of strengthening. However, the two materials are different from each other in terms of mechanical and physical properties; thus, similar strengthening technique may not be effective for both. Therefore, studies on other techniques of wrapping and surface pre-treatment of RCBs should be done to find the suitable technique for both materials.

\section{Conclusions}

Wire mesh and nonwoven geotextiles are locally available materials that can be used as RC beam strengthening material to enhance the capacity and improve performance of structures by applying according to any compatible approach. From this experimental study, a single layer of wire mesh applied using mortar may enhance the flexural strength of RCBs more than $90 \%$. The debonding of the wire mesh layer is a considerable hindrance to reach the peak limit of strength, which begins along the highly compressive stress zone. Deflection resisting capacity of these beams is also high. To produce the same deflection in wire mesh-strengthened beam and control beam, the former requires at least $90 \%$ more load than the latter. However, geotextile-strengthened beams are flexible in nature and deflects more than three times compared with the control beam when peak loads are comparatively lower than the wire mesh-strengthened beam. Crack width in geotextile-strengthened beams is less than that of the wire mesh-strengthened and control beams. This result ensures good bonding between geotextile and concrete, which provides a grip of concrete up to failure and extends up to its peak limit. The experimental results indicate $8-91 \%$ increase in flexural strength of RCBs, which can be enhanced by further treatments. Therefore, these two materials are reliable and compatible in terms of flexural strengthening of RCBs in light to medium structures under moderate loadings and environmental condition.

Furthermore, the authors recommend further research on the characteristics of wire mesh and geotextile to be applied in structures for performance improvement. Therefore, proper guidelines should be studied thoroughly to apply geotextile for flexural strengthening purposes with all possible difficulties. Adhesive requirement and surface treatment may need to be analyzed experimentally with economic feasibility analysis. Wire mesh strengthening techniques have been extensively studied previously; however, geotextile strengthening is still not available in the literature. Therefore, the use of protective measures for strengthening via wire mesh and geotextile should be investigated. These layers have thin layer of cement mortar, which may lead to decreasing the durability and thus warrant further investigation for different adverse environments because ultraviolet radiation has been reported to affect nonwoven geotextiles negatively.

Acknowledgements The experimental work was conducted at Pabna University of Science and Technology, Pabna-6600, Bangladesh. The authors are grateful to the Management, Secretary, Chairman of the Department, and the Faculty members of Civil Engineering Department for the facilities provided and cooperation rendered. The authors gratefully acknowledge the support provided by the Department of Civil Engineering, College of Engineering, Prince Sattam Bin Abdulaziz University, Saudi Arabia.

Funding Information Not applicable.

\section{Compliance with ethical standards}

Conflict of interest On behalf of all authors, the corresponding author states that there is no conflict of interest

\section{References}

1. Alhadid MMA, Youssef MA (2018) Assessment of the flexural behavior of reinforced concrete beams strengthened with concrete jackets. Eng Struct 167:108-120. https://doi.org/10.1016/j. engstruct.2018.04.026

2. Al Saadi HSM, Mohandas HP, Namasivayam A (2017) An Experimental Study on Strengthening of Reinforced Concrete Flexural Members using Steel Wire mesh. Curved Layer Struct 4:31-37. https://doi.org/10.1515/cls-2017-0004

3. Khan SU, Rafeeqi SFA, Ayub T (2013) Strenthening of RC Beams in Flexure Using Ferrocement. Iran J Sci Technol Trans Civ Eng 37:353-365. https://doi.org/10.22099/IJSTC.2013.1792

4. Si Larbi A, Contamine R, Hamelin P (2012) TRC and hybrid solutions for repairing and/or strengthening reinforced concrete beams. Eng Struct 45:12-20. https://doi.org/10.1016/j.engst ruct.2012.06.002

5. Xing G, Wu T, Liu B et al (2010) Experimental investigation of reinforced concrete t-beams strengthened with steel wire mesh embedded in polymer mortar overlay. Adv Struct Eng 13:69-79. https://doi.org/10.1260/1369-4332.13.1.69

6. Siddika A, Al Mamun MA, Alyousef R, Amran YHM (2019) Strengthening of reinforced concrete beams by using fiberreinforced polymer composites: a review. J Build Eng 25:100798. https://doi.org/10.1016/j.jobe.2019.100798

7. Qeshta IMI, Shafigh P, Jumaat MZ et al (2014) The use of wire mesh-epoxy composite for enhancing the flexural performance of concrete beams. Mater Des 60:250-259. https://doi. org/10.1016/j.matdes.2014.03.075

8. Bansal PP, Kumar M, Kaushik SK (2008) Effect of wire mesh orientation on strength of beams retrofitted using ferrocement jackets. Int J Eng 2:8-19

9. Lalaj O, Yardım Y, Yılmaz S (2015) Recent perspectives for ferrocement. Res Eng Struct Mater 1:11-23. https://doi.org/10.17515/ resm2015.04st0123

10. Žák J, Štemberk P, Vodička J (2017) Production of a textile reinforced concrete protective layers with non-woven polypropylene fabric. IOP Conf Ser Mater Sci Eng 246:012054. https://doi. org/10.1088/1757-899X/246/1/012054 
11. Ajmeri JR, Ajmeri CJ (2016) Developments in nonwoven as geotextiles. In: Advances in technical nonwovens. Elsevier, pp 339-363

12. Pakravan H, Jamshidi M, Latifi M, Neshastehriz M (2011) Application of polypropylene nonwoven fabrics for cement composites reinforcement. Asian J Civ Eng 12:551-562

13. Koutas LN, Tetta Z, Bournas DA, Triantafillou TC (2019) Strengthening of concrete structures with textile reinforced mortars: state-of-the-art review. J Compos Constr 23:03118001. https:// doi.org/10.1061/(ASCE)CC.1943-5614.0000882

14. Long JH, Paul SL, Lampo RG (1989) Bond strength between geotextiles and concrete. Geotext Geomembranes 8:113-132. https ://doi.org/10.1016/0266-1144(89)90023-X

15. Lawson CR (2016) Geotextiles in marine engineering. In: Geotextiles. Elsevier, pp 435-482

16. Kaish ABMA, Jamil M, Raman SN et al (2018) Ferrocement composites for strengthening of concrete columns: a review. Constr Build Mater 160:326-340. https://doi.org/10.1016/j.conbuildma t.2017.11.054

17. Gopinath S, Ramachandra Murthy A, lyer NR, Dharinee R (2016) Investigations on textile-reinforced concrete as cover for RC beams. Mag Concr Res 68:1040-1050. https://doi.org/10.1680/ jmacr.15.00161

18. IS: 1489-1991 Portland-pozzolana cement specification. Bureau of Indian Standards. New Delhi, India

19. IS: 516-1959 Indian standard methods of tests for strength of concrete. Bureau of Indian Standards. New Delhi, India

20. ASTM C $78 / C 78 M-18$ Standard test method for flexural strength of concrete (using simple beam with third-point loading). https ://www.astm.org/Standards/C78.htm. Accessed 27 Feb 2019

21. Claramunt J, Ventura H, Fernández-Carrasco L, Ardanuy M (2017) Tensile and flexural properties of cement composites reinforced with flax nonwoven fabrics. Materials (Basel) 10:215. https://doi. org/10.3390/ma10020215

Publisher's Note Springer Nature remains neutral with regard to jurisdictional claims in published maps and institutional affiliations. 